\title{
Las terapias cognitivo-conductuales: Una revisión
}

\author{
F. Bas Ramallo
}

Centro de Terapia y Modificación de Conducta

\section{HAZANAS DE UN TERAPEUTA PREHISTORICO}

Desde Epicteto de Hierópolis (s. I-II) hasta los recientes trabajos de Meichenbaum y Cameron (1980), es posible encontrar huellas de lo que en este siglo ha venido a llamarse terapia cognitiva. $\mathrm{La}$ idea de que el pensamiento juega un poderoso papel tanto en la creación y mantenimiento de ciertos estados emocionales como en la dirección de la propia conducta, puede constituir una vieja creencia a fuer de constituir igualmente una vieja experiencia. Nos podemos imaginar a un joven $e$ inexperto cazador prehistórico compungido y melancólico por haber perdido una pieza que le parecía fácil, siendo consolado por un compañero más experto y optimista que le sugiriese en su jerga: ¡Olvídate hombre, ya llegarán tiempos mejores! Tal individuo podría estar pretendiendo «cambiar» los negros pensamientos de su compañero guiado quizás por su propia experiencia subjetiva. $\mathrm{La}$ posibilidad de aprender y modificar nuestras actitudes en base a la propia experiencia, sin el concurso de otros, tomando como fundamento la autoobservación ha sido tratada en varias ocasiones (Ben, 1967; Dulany, 1968; Wilkins, 1971; Bandura, 1977 b), y nos permite sugerir que tales procesos tienen que haber sido «vividos» por el hombre desde épocas remotas.

Si nuestro improvisado e intuitivo terapeuta prehistórico se hubiese mantenido en una estrategia de cambio puramente verbal, tratando los aspectos esencialmente conscientes de la experiencia negativa de su compañero, buscando las «ideas y creencias irracionales», las «contradicciones», las «generalizaciones incorrectas», las «dicotomías», etc., en definitiva intentando alterar el conjunto de creencias del sujeto acerca de su propia incapacidad, diríamos en términos actuales que estaba aplicando una terapia cognitiva pura o terapia semántico-cognitiva. Su objetivo habría consistido en cambiar los pensamientos de su compañero, con la esperanza de que, una vez modificados éstos, se alterarían positivamente sus emociones y la forma de conducirse.

Pero supongamos que tal sujeto no sólo conocía el poder de la persuasión 
verbal, sino que gracias a unas extraordinarias dotes de observación había llegado a la conclusión de que los humanos también solemos conducirnos en función de los resultados obtenidos a través de nuestras propias acciones, y que nuestras actitudes cambian igualmente como consecuencia de tales resultados. Se le ofrecía, de este modo, una segunda «herramienta» que podía ser usada a fin de cambiar la postura indiferente de su compañero de caza. Ante la cerrazón de éste, le propuso llevar a cabo una prueba al objeto de intentar «convencerle» de que estaba en un error y la caza aún era posible para él. Una vez hubo aceptado que manteniéndose sentado nunca llegaría a alcanzar ninguna presa, nuestro afligido personaje se prestó a llevar a cabo el experimento. $\mathrm{El}$ astuto terapeuta, a sabiendas de que su joven compañero era un buen arquero, lo apostó en un lugar estratégico desde donde existía un máximo de probabilidades de alcanzar la pieza. Una vez obtenida ésta, la situación para el arquero resultó embarazosa. Si persistía en su incredulidad acerca de sus habilidades para la caza entraba en flagrante contradicción con los hechos, pero si reconocía tales habilidades no podía justificar sus pensamientos negativos. Es así como nuestro eminente terapeuta había inducido una disonancia cognitiva en las expectativas del sujeto. Pero, ¿por cuál de las dos alternativas se decidiría finalmente? El momento era crítico y algo había que hacer. Para el joven, las cosas seguían estando poco claras, a veces daba la impresión de que no interpretaba sus propios resultados de manera objetiva y positiva. Algo seguía funcionando mal «dentro de su cabeza». La vieja experiencia del maestro le había llevado a la idea de que cuantas más veces se repitiese una consecuencia en determinadas circunstancias, más firmemente podría creerse en ella y que si tal consecuencia era agradable y útil en lo sucesivo se llegaba a ejecutar con más frecuencia. Con este supuesto, preparó las cosas de tal manera que a su compañero le fuera fácil obtener más piezas en los días siguientes de manera que con un esfuerzo progresivo y graduado pudiese obtener éxitos repetidos. Su convincente dialéctica, en fuego cruzado con el poder reforzante de los hechos repetidos, que entraban en contradicción con los supuestos del amigo, permitieron al sagaz terapeuta prehistórico animar considerablemente a su atribulado compañero. Este segundo diseño, que somete las propias expectativas negativas del sujeto a prueba empírica de un modo combinado con la persuasión verbal, es el meollo de algunas formas específicas de modificación cognitivo-conductual.

Pero su arsenal de habilidades no terminaba aquí. Durante sus cacerías en grupo, había podido comprobar que los jóvenes aprendían mejor y más rápidamente las artes cinegéticas si durante un tiempo se dedicaban a observar detenidamente a los arqueros más diestros, y esto era mejor que cuando simplemente se les explicaba o aleccionaba verbalmente en ello. Una vez más se le ofrecía la oportunidad de mejorar, con esta tercera herramienta las habilidades y el estado de ánimo de su compañero. Dispuso sus intervenciones en la búsqueda de las presas de tal modo que el otro siempre lo pudiese observar fácilmente, avanzando progresivamente desde los gestos y los intentos más sencillos a los más complejos y animándole de continuo a que lo imitase. Le informó igualmente de que lo que se dijese a sí mismo y las imágenes que mantuviese en el transcurso de la ejecución tenían mucho que ver con el éxito en la caza. De manera que lo mejor que podía hacer era no sólo intentar imitar lo que él mismo llevaría a cabo de un modo atento y relajado, sino también imitar lo que él dijese en voz alta, o que buscase las exclamaciones o frases que más le convinieran. Tras un período de entrenamiento, el joven no sólo logró adquirir ciertas habilidades muy útiles para enfrentarse con las dificultades de la caza, sino que llegó a sentirse mucho más seguro de su capacidad para afrontarlas. 
Algunas de estas estrategias de cambio terapéutico y de conducta, y otras que comentaremos más adelante son usuales en lo que ha venido en llamarse modificación conductual-cognitiva o cognitivaconductual (CBM) (sobre el debate terminológico puede verse por ejemplo Wilson, 1978).

\section{PRECURSORES Y AUTORES MAS - REPRESENTATIVOS DE LA CBM}

Si nuestro hipotético terapeuta prehistórico quizá ya «sabía hacer» estas cosas, de lo que se trata ahora es de buscar la estructura formal de estos procedimientos, una teoría con sólida base empírica y determinar las variables específicas que caracterizan el cambio. La CBM trata de aunar los resultados experimentales, observacionales y clínicos obtenidos por la psicología científica en las últimas décadas, bajo el viejo supuesto de que los procesos cognitivos juegan un importante papel y merecen una investigación precisa tanto por sí mismos (Neisser, 1967) como por su poder causal en el cambio de conducta (Bandura, 1969, 1974, 1977 a, 1977 b, 1978, 1980). Las bases lejanas y próximas de esta corriente podemos encontrarlas citadas, entre otros, en Ellis $(1961,1962)$, Ellis y Grieger (1977), Mahoney (1974), Meichenbaum (1977), Foreyt y Rathjen (1978), Kendall y Hollon (1979), Beck, Rush, Shaw y Emery (1980), Turk, Meichenbaum y Genest (1980), y Meichenbaum y Cameron (1980). Algunos editores, como Franks y Wilson, insertan todos los años los trabajos más significativos llevados a cabo en el campo y una nueva revista editada por Mahoney desde la universidad de Pensylvania (Cognitive Therapy and Research) fomenta esta corriente con un carácter interdisciplinario. En 1976 se celebró en Nueva York la primera convención sobre modificación cognitivaconductual.

Teniendo presente que las aproximaciones clínicas a la CBM combinan las prácticas terapéuticas cognitivo-semánticas con las terapias de conducta, los precursores de esta modalidad surgen de ambas corrientes. Raimy (1978) ha trazado recientemente la evolución de las terapias cognitivo-semánticas. Entre los precursores podemos encontrar autores tan distintos como Kant, Adler (1927), Sullivan (1947), Janet (1907), Dubois (1909), Cone (1922), Korzybsky (1933), Johnson (1946), Shaffer (1947), Snygg y Combs (1949) y Low (1950) antes de iniciarse la década de los sesenta, y a Pastore (1952), Rotter (1954), Kelly (1955), Allport (1955) y Phillips (1957) durante esta década. De 1960 a 1969 los trabajos que han incidido sobre la CBM se multiplican considerablemente, pudiendo ser citados entre otros: Frank (1961); Vygotsky (1962), Luria (1961, 1969), Ellis (1962), Lazarus (1966), Velten (1968), Liebert y Morris (1967), Beck (1967), Marlett y Watson (1968) y Bandura $(1961,1969)$. Los autores de esta última década, desde campos epistemológicos, experimentales o clínicos distintos, utilizando procedimientos terapéuticos esencialmente cognitivos (como pueda ser en el caso de Frank) o combinados (como puede apreciarse en Lazarus, Beck o Bandura), prestaron vías de interpretación e.intervención alternativas, establecieron críticas o sirvieron de base a otros trabajos que intentaron mediatizar con éxito variable los procedimientos terapéuticos derivados de las teorías del condicionamiento clásico y operante aplicados a humanos.

Las referencias a trabajos sobre CBM efectuados en la década de los setenta llenaría muchas páginas. La ley del crecimiento exponencial de Price (1963) constituye una barrera que de algún modo debemos obviar. Mahoney y Arknoff (1978) efectuaron una revisión de las terapias cognitivas y de autocontrol que posteriormente ha sido muy comentada (Wilson; 1978; Meichenbaum y Cameron, 1980): De esta época podemos citar de manera especial a Cautela (1971), Goldfried (1971), Suin y Richardson (1971), D'Zurilla y Goldfried (1971), 
Kazdin (1973), Spivack y Shure (1974), Mahoney (1974, 1977, 1979), Meichenbaum $(1974,1976,1977,1979)$, Spivack, Platt y Shure (1976), Turk (1975) y Beck (1976). Si bien estas referencias no pueden entenderse como exhaustivas, los autores citados constituyen algo así como la crema de la nueva corriente.

\section{PROBlemas QUe han FACILITADO EL DESARROLIO DE LA CBM}

En líneas generales podemos estimar que el desarrollo de la CBM sigue líneas evolutivas paralelas a las de la polémica suscitada en los últimos tiempos acerca de la validez del enfoque conductista especialmente en el ámbito terapéutico. Sin embargo, la CBM lejos de presentarse como el desarrollo de un polo opuesto, en donde la: línea cognitivista pudiera prevalecer, se presenta más bien como un intento de síntesis (Meichenbaum, 1977; Meichenbaum y Cameron, 1980; Kendall y Hollon, 1979).

Al margen de la insatisfacción personal por los resultados de la práctica terapéutica conductista, los precursores de esta nueva orientación, que de hecho procedían de diversas escuelas y encaraban el quehacer terapéutico con metodologías diversas, podían basar su descontento en la acumulación de datos ya existentes sobre la inadecuación del modelo no mediacional.

Si el organismo no responde a estímulos físicos externos puros, sino al estímulo como «percibido» (Miller, 1935; Dulany, 1968), llegándose más tarde al límite de considerar el propio condicionamiento palpebral en humanos como mediado por el significado descubierto en el Estímulo Condicionado (Horton y Turnage, 1976; Maltzman, 1977; Genings, Crosland, Loveless, Murray y George, 1978); 'si en el condicionamiento semántico la generalización de la respuesta condicionada se da más en función del significado de otras palabras que por su similaridad fonética (Maltzman, 1968); si la generalización del arousal asociado al estímulo condicionado se da también de acuerdo a un gradiente semántico más que fonético (Paulov, 1955; Platonov, 1959; Razran, 1939, 1961, 1965); si el ser humano puede verse como una criatura autoestimulatoria (Mahoney, 1974) y los trabajos sobre autoestimulación simbólica cubren un campo tan vasto que difícilmente podríamos resumir aquí (la mejor documentación al respecto puede verse en Bandura, 1969 y Mahoney, 1974); si el conocimiento de las contingencias de refuerzo influyen significativamente sobre la ejecución. (Spielberger y De Nike, 1966), y los mismos resultados se obtienen barajando un paradigma de condicionamiento clásico (Notterman, Schonenfeld y Bersch, 1952); si en el proceso de aprendizaje vicario (Bandura, $1969,1971,1977)$ y especialmente en el proceso de adquisición de la respuesta, se dan una serie de subprocesos cognitivos que son considerados muy convenientes para una ejecución adecuada; si el modelo de condicionamiento inmediato queda seriamente cuestionado en base a trabajos de sólida base empírica (Bandura, 1969), siendo confirmados repetidamente (Bandura, 1974; Brewer, 1974; Mahoney, 1974; Meichenbaum, 1977). Si en el campo de la investigación básica y de la estructura teórica de los modelos del condicionamiento clásico y operante surgian estas lagunas, ¿nos podemos extrañar de que se buscasen fórmu: las alternativas más acordes con los datos experimentales?

Otro campo desde el que confluían las dudas acerca de la adecuación de estos modelos para explicar la conducta humana fue el psicolingüístico. La polémica se inició con fuerza a finales de la década de los 50, cuando Chomsky. (1959) estableció una crítica erosiva al trabajo sobre conducta verbal realizado por Skinner (1957), y cuya difusión en el mundo académico occidental fue muy notable en comparación con la ofrecida al trabajo de Skinner (Bayes, 1977). Cuando mucho más tarde:Mac Corquodale (1970) y Richelle (1972) replicaron a los argumen- 
tos chomskianos era demasiado tarde. La psicolingüística ya había desarrollado otros derroteros muy alejados de la orientación skinneriana, y la CBM no sólo ha hecho por ahora poco uso de esa corriente, sino que uno de sus más destacados representantes (Meichenbaum, 1977) se ha adscrito a los modelos rusos de Luria (1961, 1969) y Vygotsky (1962) para desarrollar técnicas de autoinstrucción inicialmente orientadas al cambio de la conducta infantil *.

En el área terapéutica encontramos otra fuente de problemas. La crítica llevada a cabo por Breger y McGaugh (1965) tuvo en su tiempo mucha resonancia. Según estos autores, las teorías del aprendizaje no podían servir de base para explicar los procedimientos terapéuticos conductuales, así como para fundamentar una teoría de la neurosis. La asociación entre la teoría conductista y la práctica terapéutica se había basado más bien en el uso de las mismas palabras que en el empleo de los mismos métodos. Es decir, términos como «estímulo», «respuesta» y «condicionamiento», cuya definición operativa ocupa un espacio en la psicología experimental, quedando de este modo asociados con un método científico de trabajo; eran engañosa $e$ inadecuadamente trasladados al campo de la psicoterapia y de la psicopatología humanas. De forma paralela a la crítica de Chomsky (1959) ya citada, los autores reformularon los procesos de aprendizaje estableciendo un modelo mediador central tal como el del «almacenamiento y recuperación de la información», emparentado con el aprendizaje cognoscitivo de Miller, Galanter y Pribram (1960) o Tolman (1932). El concepto esgrimido se basa en la necesidad de una "estrategia» para que el individuo pueda obtener ciertos logros en su medio. Este concepto, por cierto de larga tradición, podía ofrecer una alternativa para explicar mejor los fenómenos de la generalización, a la vez que presentaba una mayor utilidad en la formulación teórica de la neurosis; viendo ésta como un proceso en el que lo que se aprende es un conjunto de estrategias centrales (o un programa) que guía la adaptación de un individuo a su medio. Del mismo modo que en el aprendizaje del lenguaje no - se aprenden sólo conjuntos de respuestas (palabras y oraciones), sino, además, algún tipo de estrategias o de planes internos (gramática), en la neurosis no se aprenderían un conjunto de síntomas o hábitos de conducta, sino estrategias centrales que conducirían tanto a fenómenos manifiestos (actos compulsivos, tics, etc.), como a otros menos observables (miedos, ansiedad, etc.). Este concepto de «estrategias» ha sido retomado por Meichenbaum (1977) y Meichenbaum y Cameron (1980), bajo el rótulo de fenómenos metacognitivos.

Las argumentaciones de Breger y Mc Gaugh (1965) fueron contestadas por Wiest (1967) y Rachman y Eysenck (1966). La réplica de Wiest se centró especialmente en la crítica efectuada por aquellos autores a la teoría del aprendizaje, los modelos del condicionamiento simple, la teoría del refuerzo, etc. Dejando a un lado las críticas de Koch (1964) a la filosofía de la ciencia positivista lógica (los aspectos filosóficos del debate pueden verse ilustrados por ejemplo en Allport, 1955; Mahoney, 1974; Wolpe, 1976, 1978; Beck y Mahoney, 1979; Mahoney y Kazdin, 1979), Wiest: a) echa de menos un mejor conocimiento por parte de esos autores del desarrollo teórico y experimental de los problemas del área llevado a cabo en la década anterior; b) critica la falta de una clara distinción

* Constituye, a nuestro entender, un paso positivo para la integración no sólo el acercamiento interparadigmático entre cognitivistas y conductistas, sino el aprovechamiento de los avances conseguidos en la misma disciplina dentro de otras áreas culturales. El chauvinismo en el desarrollo cultural es por desgracia demasiado frecuente y cualquier paso bien fundamentado para superarlo debe ser alentado. Por otro lado, quizás constituya un requisito de toda empresa paradigmática (KuHN, 1962). 
entre observación e interpretación (y por tanto el fracaso al no distinguir entre observación e inferencia o constructo); c) critica el establecer de partida una definiciớn errónea del concepto de aprendizaje (y por tanto la deducción de consecuencias irrelevantes para la posición conductista); d) la confusión del estímulo con la respuesta al categorizar los fenómenos cognitivos mediadores (ya Skinner en 1963 había hecho notar que la imaginación es una forma de conducta, no un estímulo); $e$ ) refuta la interpretación del síntoma fóbico como una simple operante singular; f) hace hincapié en que los datos de la observación pueden conceptualizarse de distintos modos y que si bien un modelo mediacional utilizando variables intervinientes y constructos (o «estrategias») puede establecer su propia teoría, también resulta legítimo un sistema conceptual que permanezca más estrechamente ligado al lenguaje de la observación, y por tanto al de los hechos públicamente observables (conducta y medio en el caso de la psicología). En relación a la crítica de Chomsky (1959) a Skinner (1957), Wiest ve como una inferencia, no requerida por la regularidad de la conducta verbal, la creación de constructos gramaticales (estructuras o estrategias internalizadas para el habla) necesarios para justificar la producción y comprensión del habla. Dice así el autor: «Mostrar que el niño habla como lo podría predecir una teoría de la adquisición de la gramática no es lo mismo que pretender que el niño ha internalizado las reglas gramaticales. Lo último implica una inferencia teórica que podría concebirse como útil pero que como todas las inferencias no es lógicamente exigida» (Wiest, 1967, p. 219).

Por último vamos a comentar el problema de la generalización, verdadero caballo de batalla en la práctica de las terapias conductuales. Breger y $\mathrm{Mc}$ Gaugh (1965) establecían que una auténtica ventaja al fijar una «estrategia» central consistía en enclavar la generalización en su núcleo, «en vez de ser importada secundariamente, como ocurre en los conceptos E-R de estímulo y generalización de la respuesta» (p. 356). Pero para Wiest, este enfoque no ayuda a explicar los fenómenos de equipotencialidad de la respuesta y de la adaptabilidad del organismo a situaciones nuevas. Sólo disuelve el problema mediante una definición. La generálización es supuesta en lugar de intentar explicarla enunciando las condiciones en que ocurre. Lo que se hace es rotular un fenómeno, dejando de lado el problema empírico y convirtiendo su solución en una pseudoexplicación.

Los tópicos señalados han sido algunos de los que han caracterizado la polémica acerca de la teoría y la adecuación a humanos del modelo conductista en la década de los 60. Era necesario este breve periplo para darse una idea de la compleja situación de la que se partía.

\section{CORRIENTES DE INFLUENCIA MAS IMPORTANTES}

Si bien este tipo de problemas de caráeter general rodeaban ( $y$ en alguna medida continúan rodeando) el ambiente de trabajo de los terapeutas con orientación conductual de aquella época, cuatro focos de influencia han incidido de un modo más específico sobre los diseños de la CBM (Kendall y Hollon, 1979), a saber:

1.) El primero reside en el punto de vista que establece que las cogniciones (por ejemplo los pensamientos) están sujetos a las mismas leyes que la conducta manifiesta (Cautela, 1967; Homme, 1965; Hullman, 1970). Esta idea no es nueva, ya Skinner la había formulado aunque sin suficiente apoyo empírico mucho antes (Skinner, 1953).

2) La segunda influencia procede de la corriente semántica-cognitiva, que establece que las creencias, las expectativas, las atribuciones y otras actividades cognitivas son centrales para producir, predecir y comprender la conducta psicopatológica y los efectos de la intervención terapéutica. Los procedimientos de intervención de Ellis (1962) y Beck 
$(1963,1976)$ se han visto muy influidos por esta orientación.

3) Recientes trabajos teóricos dentro de una reformulación de las teorías del aprendizaje, tales como la noción de autoregulación de Kanfer (1970), y el concepto de autoeficacia de Bandura (1977) han ofrecido la posibilidad de presentar los procesos cognitivos dentro de formulaciones verificables que pueden integrarse fácilmente en los paradigmas conductuales. Por ejemplo, Behn (1977) ha ofrecido un modelo de la depresión basado en déficits de autocontrol apoyado en las ideas de Kanfer (1970).

4) La última influencia procede del propio deseo de integrar estrategias de tratamiento cognitivas con el manejo de contingencias conductuales en orden a superar ciertos problemas y obtener resultados significativos. Casi todos los procedimientos de la CBM conllevan esta combinación, aunque en algunos casos se presenten de un modo explícito $y$ en otros no. Más adelante haremos hincapié sobre ello.

\section{LA CBM Y SU CONEXION CON OTROS SISTEMAS DE TERAPIA}

Si bien en la década de los 50 y 60 , las corrientes terapéuticas derivadas de la teoría del aprendizaje podían centrarse en las alternativas de Dollard y Miller (1950), Wolpe (1958) y Eysenck (1960) y la puramente skinneriana, en los años setenta es preciso añadir los procedimientos derivados de la teoría del aprendizaje social de Bandura (1969) y los de la CBM. Debido a que Dollard y Miller trabajaron realmente con el modelo psicoanalítico (aunque si bien utilizando la terminología derivada de la teoría del aprendizaje de Hull), no vamos a incluirlo en esta exposición. Por una razón similar tampoco incluimos el intento de Peterfreund y Schwartz (1971) de reemplazar el lenguaje psicoanalítico por otro derivado del procesamiento de la información, aun cuando estos procesos tengan cada vez un interés mayor dentro del ámbito de las terapias cognitivas (ver por ejemplo Hollon y Beck, 1979).

Antes de abordar el estudio de la CBM vamos a realizar una breve síntesis de las tres tendencias que están presentes junto a ella, a fin de adquirir una perspectiva que nos permita enjuiciar los contrastes y similitudes existentes:

a) El «análisis conductual aplicado», de orientación skinneriana, está basado en los principios y procedimientos del condicionamiento operante. Su publicación más importante es la revista Journal of Applied Bebavior Analysis (JABA). Algunas de las características más importantes de este enfoque son:

1. El uso explícito de variables objetivas y conductuales y de modo especial la tasa de respuesta como variable dependiente.

2. Al margen de las influencias genéticas, el control de la conducta humana se establece a través de las influencias del entorno.

3. Su insistencia en el estudio de la conducta del organismo individual.

4. La confianza en los principios del refuerzo y el castigo para explicar el mantenimiento y cambio de la conducta.

5. Su campo de aplicación se inició con el estudio del retraso y el deterioro de las capacidades cognitivas individuales (niños y adultos retardados e instituciones para pacientes psicóticos), y que con posterioridad se han ampliado a otros campos.

b) Otra corriente es la conocida como modelo neoconductista mediacional ER. Se ha desarrollado en especial a través de Wolpe (1958), Eysenck $(1960,1964)$ y Rachman (1963). Se basa esencialmente en la aplicación del condicionamiento y contracondicionamiento clásicos al tratamiento de la conducta anormal, en especial al campo de la neurosis. Su apoyo histórico se centra en Pavlov, Guthrie, Hull, Mowrer, Miller y Dollard.

Esta corriente siempre se basó en un esquema E-R extendido al medio cognitivo. Su desarrollo permite apreciar dos 
orientaciones según el tipo de variables usadas con más frecuencia:

1. La tendencia original, en especial de Wolpe, donde privan las variables fisiológicas, conductuales y las imágenes, y

2. otra corriente más cognitiva y dentro de la cual podemos citar a Homme (1965), Cautela (1961) y Staats $(1968,1970,1975)$, este último creador de la teoria trifuncional del aprendizaje del conductismo social.

El rasgo que caracteriza a todos estos procedimientos y autores, es el de que las mismas leyes que gobiernan la conducta manifiesta presiden los procesos encubiertos a través del esquema E-R.

c) En la teoría del aprendizaje social la figura más destacada es sin duda, Bandura $(1969,1974,1977$ a, 1977 b, 1978, 1980). Tanto la conducta desviada como la social es desarrollada y mantenida en base a tres sistemas de regulación:

1. Un primer sistema formado por el conjunto de pautas de respuesta que están bajo el control de estímulos externos. El condicionamiento clásico de cuenta de ellas.

2. Un segundo conjunto de respuestas está bajo el control del refuerzo externo. El condicionamiento operante las explica.

3. El tercer sistema regulador, y el más importante se da a través de los procesos mediacionales cognitivos.

Podemos resumir las características más sobresalientes de esta corriente en los siguientes puntos:

- Presentación del «modelado» como una forma de aprendizaje sin refuerzo manifiesto.

- Se presenta el condicionamiento clásico no como un proceso de aprendizaje automático, sino que las respuestas condicionadas son vistas como autoactivadas sobre la base de las expectativas previamente aprendidas. De forma similar, el refuerzo no actúa de modo automático sobre la conducta, sino que se interpreta como una fuente de información y de incentivo que regula la conducta.

- Entre la conducta y su entorno existe una interacción recíproca. $\mathrm{Al}$ tópico conductista ortodoxo "Cambie sus contingencias y usted cambiará su conducta», Bandura añade «Cambie la conducta y usted cambiará las contingencias» (Bandura, 1977 a, p. 203).

- Las influencias causales que tienen los pensamientos sobre la conducta, permiten al hombre autodirigir la adquisición, el mantenimiento y la activación de sus propias conductas.

- La clave para llevar a cabo el cambio de conducta reside en el concepto cognitivo de autoeficacia. Las expectativas de autoeficacia son determinantes para que el sujeto persevere y se someta a situaciones que evocan ansiedad y utilice estrategias de enfrentamiento (coping). El feedback producido en la propia ejecución (por ejemplo en el modelado participante), en la información vicaria (por ejemplo en el modelado simbólico), en los cambios fisiológicos (por ejemplo durante la desensibilización sistemática) y en la persuasión verbal (por ejemplo en la psicoterapia tradicional), son procedimientos normales para modificar las expectativas de autoeficacia.

En razón al carácter dialéctico de la teoría del aprendizaje social, el cambio directo de la conducta es el medio más poderoso para alterar los mecanismos cognitivos de autoeficacia (Bandura, 1977 b). En este sentido, por tanto, el cambio puede sobrevenir o bien directamente a través de los mecanismos operantes o clásicos del condicionamiento, o bien cambiando las expectativas de autoeficacia que debería concluir en un cambio de conducta.

Tratemos ahora de entrar en el terreno de la CBM y su problemática.

\section{TERAPIAS CONDUCTUALES- COGNITIVAS}

*La CBM es una rúbrica que se aplica a una variedad de técnicas terapéuti- 
cas que se basan en varios modelos conceptuales diferentes» (Meichenbaum y Cameron, 1980 , p. 4). Los modelos teóricos, los procedimientos y los objetivos son variados y no reflejan ningún armazón teórico único. No obstante, Mahoney y Arknoff (1978) han indicado tres características comunes a estos modelos:

1. Tanto las conductas adaptativas o inadaptativas como las pautas afectivas van acompañadas de procesos cognitivos (atención selectiva, códigos simbólicos, etcétera).

2. Estos procesos cognitivos son activados funcionalmente mediante procedimientos generalmente isomorfos con aquellos otros obtenidos del aprendizaje humano en el laboratorio.

3. La tarea del terapeuta es la de un educador-diagnosticador que evalúa los procesos cognitivos inadecuados y consiguientemente estructura las experiencias de aprendizaje idóneas para alterar estos pensamientos y de paso, las pautas afectivo-conductuales con las cuales correlacionan (Mahoney y Arknoff, 1978, página 692).

A los factores comunes indicados habría que añadir un cierto compromiso en el uso de los procedimientos de la terapia de conducta para la provocación del cambio. Si bien desde la terapia cognitiva y de autocontrol (revisada por Mahoney y Arknoff), el objetivo puede consistir en modificar las cogniciones a través de los procedimientos conductuales, ciertamente que los objetivos pueden ser tanto $\operatorname{cog}$ nitivos como conductuales o ambos conjuntamente (ver Tabla I de Kendall y Hollon, 1979, p. 4).

Pero en tanto que hay factores comunes, como ya hemos apuntado, también están presentes diferencias importantes. Veamos algunas de las que han sido senaladas por Meichenbaum y Cameron (1980).

1. La base teórica de los procedimientos puede ser muy variada (condicionamiento clásico $\mathbf{u}$ operante, procesa- miento cognitivo de la información, aprendizaje social, etc.).

2. Pueden ser considerados aspectos diferentes de la experiencia cognitiva (creencias, atribuciones, expectativas, automanifestaciones de coping e imágenes, solución de problemas, etc.).

3. Considerable variabilidad respecto al mejor punto de intervención en el complejo cognición - afecto - conducta - consecuencias.

4. Diferentes estrategias para la intervención (ataque frontal a las creencias irracionales, contraste empírico de las creencias, etc.).

5. Diferencias respecto al estilo de la intervención (desde la directiva a la colaboradora).

6. En relación al énfasis dado al uso explícito de los procedimientos de la terapia de conducta, pueden encontrarse diferencias muy notables, etc.

De manera que del mismo modo que la terapia de conducta nunca fue un conjunto monolítico (Wilson, 1978), la CBM tampoco lo es.

Siguiendo la línea expositiva, vamos a distinguir lo que son los procedimientos terapéuticos del estudio de los procesos y las teorías del cambio que han tratado de integrar los modelos mediacionales en el cambio de conducta.

\section{VI.1. Procedimientos terapéuticos en la CBM}

Con el esquema ofrecido por Mahoney y Arknoff (1978) pueden distinguirse tres grandes grupos de terapia conductual-cognitiva (o cognitivo-conductual, según se prefiera):

a) Psicoterapias racionales.

b) Terapias de habilidades de enfrentamiento (coping).

c) Terapias de solución de problemas.

Intentemos brevemente dar una visión de cada una de ellas. 


\section{a) Psicoterapias racionales}

Dentro de este grupo vamos a señalar las características esenciales de la terapia racional-emotiva (RET) de Ellis (1962), el entrenamiento en autoinstrucción de Meichenbaum (1973) y la terapia cognitiva de Beck (1976). Albert Ellis se presenta como telón de fondo en los trabajos de Meichenbaum y Beck. A su vez Ellis parece haber estado bajo la influencia directa de Adler, precursor de terapeutas cognitivos tales como Rotter, Kelly y Eric Berne (Raimy, 1975; Murray y Jacobson, 1978).

Antes de abordar los criterios de la RET de Ellis hemos de indicar que ya en 1959 señalaba: «El doble enfoque de la terapia, que va implícito en el término psicoterapia racional-emotiva, indica también que es algo más que un método didáctico o pasivo ya que, además de la importancia de la discusión verbal, insiste en el trabajo, la acción, el esfuerzo y la práctica. Eso es exactamente lo que hace la RET: utiliza el análisis lógico y la persuasión racional para inducir al paciente para actuar y trabajar frente a sus actitudes neuróticas $\mathrm{y}$ hábitos» (Ellis, 1962 , p. 122), y en su libro «Psicoterapia racional emotiva» hacía la siguiente observación a sus pacientes: «... no es lo que les dice el terapeuta lo que en definitiva va a ayudarles a vencer sus perturbaciones emocionales, sino lo que el paciente baga con lo que el terapeuta les diga» (Ellis y Harper, 1961, p. 7). Este apremio para la acción es pues un ingrediente en la terapia racional-emotiva, de ahí las dificultades que siempre existen en estos procedimientos al intentar evaluar el peso terapéutico relativo al enfoque verbal frente al conductual en la explicación del cambio de conducta.

De cualquier modo, no sin razón, ha sido calificada como terapia racional en virtud de su hincapié en modificar la forma en que la gente con problemas emocionales construye su mundo y las creencias irracionales que sustentan. Para Ellis existe una clara correlación entre pensamientos irracionales y perturbacio- nes emocionales. Debemos cambiar, por tanto, el sistema de creencias básico del sujeto si queremos que en un futuro no vuelvan a surgir sus problemas. No basta con un cambio localizado en las áreas cognitivas de conflicto que de modo específico pueda presentar el sujeto. Es precisa una remodelación total del set de creencias a fin de ofrecerle una base amplia de postulados racionales que le permita en un futuro poder abordar cualquier problema de su mundo emocional. $\mathrm{Si}$ no se hiciese así los conflictos volverían a surgir en otras áreas.

En este sentido, también la RET puede verse como una estrategia de coping especialmente orientada al campo de la remodelación cognitiva y, en efecto, así es como lo ha desarrollado Goldfried en 1974 con la denominación de «Reestructuración racional sistemática》 (Goldfried, 1971; Goldfried, Decenteceo y Weinberg, 1974). Entre las creencias irracionales más frecuentes del hombre que vive inmerso en el mundo occidental Ellis destaca doce que analiza detalladamente, presentando su inadecuación lógica y práctica para cada una de ellas y ofreciendo a continuación las alternativas que a su juicio son las adecuadas.

Las pautas concretas de la aplicación de la RET incluyen al menos las siguientes fases:

1. Presentación y persuasión al cliente de la filosofía contenida en la RET.

2. Identificación de los pensamientos irracionales a través de las manifestaciones del cliente y del feedback del terapeuta.

3. Cambio de las ideas irracionales y reinterpretación racional y objetiva de los hechos que las han producido.

4. Repetición del ensayo cognitivo a fin de obtener del sujeto las automanifestaciones racionales a partir de los hechos originales.

5. Una serie de tareas conductuales (que Ellis llamaba «ejercicios para perder la vergüenza»), orientadas a generar reacciones racionales donde antes eran irracionales y a favorecer la pérdida de 
la ansiedad asociada a la situación interpersonal, es decir, una forma de entrenamiento en competencia social.

Dentro de este grupo de psicoterapias racionales veamos ahora el modo de realizar el entrenamiento en autoinstrucción de Meichenbaum $(1973,1977)$.

Dos fuentes de información son consideradas aquí:

1. La RET de Ellis (1962) ya comentada.

2. El criterio de Luria (1961) acerca de la forma en que los niños desarrollan el habla interna y el control verbal-simbólico sobre sus propias conductas. En un principio, la conducta de los niños está regulada por las instrucciones de personas adultas, posteriormente son ellos mismos los que las regulan a través del uso de autoinstrucciones verbales manifiestas, internalizándose éstas finalmente como autoinstrucciones encubiertas.

Podemos distinguir tres fases en el desarrollo del procedimiento:

1. Entrenamiento del paciente a fin de que aprenda a identificar y udarse cuenta» de sus pensamientos inadecuados.

2. El terapeuta modela la conducta adecuada a la vez que verbaliza las estrategias de acción eficaces para la tarea. Estas verbalizaciones incluyen:

- El sistema de tareas requerido.

- Autoinstrucciones que orientan la ejecución de modo graduado.

- Automanifestaciones tendentes a contrarrestar la preocupación por los errores.

- Autorrefuerzo encubierto por las ejecuciones llevadas a cabo con éxito.

3. En esta fase el cliente ejecuta la tarea conductual a la vez que verbaliza en voz alta las instrucciones apropiadas ofrecidas por el terapeuta, y a continuación repite el ensayo dándose las autoinstrucciones de manera encubierta. El feedback del terapeuta durante esta fase ayuda a estructurar los pensamientos adecuados y pertinentes a la tarea.
De nuevo nos encontramos con el momento de establecer la efectividad del procedimiento enfrentándonos con el mismo problema que ya apuntábamos en el caso de la RET. El propio Meichenbaum (1977) toma de Karnes (1970) la siguiente cita: «... la característica distintiva de los programas de autoinstrucción es la unión de las verbalizaciones con las ejecuciones sensorio-motoras» (p. 40). La presencia del modelado, el refuerzo verbal y motor externos, el feedback verbal del terapeuta y el autorrefuerzo, son como hemos visto, ingredientes normales del entrenamiento en autoinstrucción. De manera que también aquí nos vemos obligados a preguntarnos: ¿Qué factores son los decisivos en este esquema? $\{$ Los puramente racionales, que parecen ser necesarios para justificar la denominación del método como psicoterapia racional, o la clase de contingencias de reforzamiento y modelado presentes en el programa? De manera que si bien el objeto de la terapia consiste en cambiar unos hábitos de pensamiento por otros, los medios de que se vale no son puramente verbales y en este sentido su denominación como terapia racional debe colocarse entre comillas. De todos modos, según el autor, su incorporación al tratamiento de los problemas de sujetos con ansiedad al habla, en niños impulsivos y en esquizofrénicos institucionalizados produce cambios significativos.

Y lo mismo ocurre con la tercera variante, la terapia cognitiva de Beck de 1976. También aquí el objetivo consiste en obtener pautas de pensamiento racionales y adaptativas. La diferencia entre Ellis y Beck consiste en que mientras el primero trata de remodelar todo el sistema de creencias irracionales del sujeto, Beck se ciñe a lo que él llama «las cualidades estilísticas de las cogniciones del cliente», centrando su estudio de forma especial en la conducta depresiva. Otra diferencia que podría señalarse es un mayor énfasis en la persuasión verbal y el método deductivo en Ellis frente al diseño de procedimientos empíricos a fin de contrastar las «hipótesis» negativas 
de los sujetos en Beck (Beck et al. 1980). Nos encontramos por tanto, con procedimientos inductivos para provocar el cambio. En el año 1967 definió cinco distorsiones cognitivas que caracterizan el procesamiento de la información del depresivo (Beck, 1967, pp. 234-235). Estas distorsiones provocan la atención selectiva del sujeto $\mathrm{y}$ una anticipación inexacta de las consecuencias, manteniendo una elevada creencia negativa respecto a sí mismo, respecto a su mundo y a su futuro.

Las etapas del entrenamiento en la terapia cognitiva de Beck podrían ser formuladas de un modo esquemático del siguiente modo:

1. Ilustrar al cliente en la teoría cognitiva de la depresión.

2. Ayudar al sujeto a «reconocer» sus pensamientos inadecuados, gran parte de los cuales son denominados «pensamientos automáticos».

3. Intento de validación empírica de sus pensamientos y la correlación de éstos con sentimientos indeseables.

4. Sustitución por otros más adaptativos y de base más objetiva.

5. Uso del feedback y del refuerzo del terapeuta.

6. Utilización de una lista de actividades precisas, tareas graduadas en el ámbito individual y social a fin de obtener éxitos sucesivos.

Vemos, por tanto, la presencia de una combinación explícita de procedimientos cognitivos $y$ otros conductuales. Como ya hemos señalado, en los tres procedimientos de intervención mencionados la denominación común de «terapias racionales» debe ser considerada en función de los objetivos perseguidos prioritariamente (el cambio en las cogniciones), más que por los medios empleados.

\section{b) Terapias de babilidades de enfrentamiento (coping)}

Otro grupo general de estrategias terapéuticas que han surgido durante la úl- tima década podrían ser rubricadas bajo la denominación amplia de «terapias de habilidades de enfrentamientơ». Su intención consiste en entrenar al sujeto en ciertas habilidades a fin de que las utilice en futuras situaciones evocadoras de ansiedad aun cuando éstas pudieran ser muy variadas. En este sentido el coping contrasta con la desensibilización sistemática de Wolpe, ya que ésta tiende a centrar el tratamiento sobre jerarquías específicas en el ámbito estricto de los problemas que presenta el cliente.

Podríamos citar el madelado encubierto de Kazdin (1974), la desensibilización modificada de Goldfried (1971), el entrenamiento en el manejo de la ansiedad de Suin y Richardson (1971) y la inoculación de stress de Meichenbaum y Cameron (1973).

También aquí, junto a una serie de factores propiamente cognitivos, vemos aparecer otros más característicos de la terapia de conducta, como el entrenamiento en autorrelajación, el adiestramiento en coping imaginario, los ensayos de conducta y la asignación de tareas reforzantes «in vivo», de forma que una vez más los programas de reestructuración cognitiva y los conductuales se hallan entrelazados. Veamos brevemente las etapas del entrenamiento en «inoculación de stress» de Meichenbaum y Cameron (1973).

1. Una primera fase educacional, en donde se le ofrece al cliente una estructura conceptual para que comprenda la naturaleza de sus reacciones, es decir, para que pueda «explicárselas». Esta estructura varía con el tipo de problema.

2. La segunda fase es de ensayo y aprendizaje, enseñándole al sujeto las habilidades precisas para manejar una serie de mediadores encubiertos (autorelajación activa, imaginación y autoinstrucción), necesarios para enfrentarse con situaciones fóbicas o ansiógenas, las cuales a su vez se subdividen en una serie de etapas intermedias de acercamiento.

3. Esta última fase es de aplicación, procediendo mediante modelado y re- 
plicación a enfrentar al sujeto a una serie de estresores en el laboratorio. En esta fase se usan las técnicas de autoinstrucción descritas anteriormente.

Veamos ahora sucintamente las terapias de solución de problemas.

\section{c) Terapias de solución de problemas (Problem-Solving)}

Si bien la investigación sobre las deficiencias en la resolución de problemas parece estar relacionada con disfunciones mediacionales, y se encuentran con frecuencia en los déficits de ejecución, sus aplicaciones clínicas y su base experimental es escasa. Se trata de nuevo de esquemas combinados cognitivo-conductuales. El trabajo de Spivac y Shure (1974) puso de manifiesto que existía una diferencia consistente entre poblaciones de sujetos «normales» $\mathrm{y}$ «desviados» en su habilidad para usar medios y anticipar consecuencias de varias opciones de respuesta. Algunos campos en los que se ha trabajado dignos de mención podrían ser el de los niños inadaptados, la conducta suicida, los trastornos geriátricos y la prevención de desajustes, Algunas revisiones de este campo, de interés relevante para la clínica, pueden verse en D'Zurilla y Goldfried (1971), Mahoney (1974), Spivac y Shure (1974), Spivac, Platt y Shure (1976), Shure y Spivac (1978) y Heppner (1978).

\section{VI.2. Teorfas del camblo en la CBM}

Las teorías más importantes para dar cuenta del cambio de conducta, sus requisitos y sus procedimientos proceden, desde un punto de vista cognitivo y conductual, de Bandura (1977 b) y Meichenbaum $(1976,1977)$. La teoría de la alteración del nivel de autoeficacia de Bandura, ya fue presentada de manera resumida al tratar la teoría del aprendizaje social. Meichenbaum reconoce de manera explícita la influencia y el paralelismo de su teoría del cambio en relación a los trabajos de Bandura (ver por ejemplo Mei- chenbaum y Cameron, 1980; Meichenbaum y Butler, 1980; Meichenbaum, 1977), y aún más estrechamente con la CBM en general. En este autor encontramos una teoría que intenta especificar las condiciones necesarias $\mathrm{y}$ suficientes para provocar el cambio. Meichenbaum (1977) sugiere que una terapia efectiva provoca en el cliente cambios en tres dominios:

1. En las conductas del cliente, que son alteradas (y por consiguiente en las relaciones con su entorno).

2. El cliente modifica las imágenes y su habla interna, es decir, aprende a interpretar su mundo, a sí mismo y a. sus conductas de una manera que resulta de más valor heurístico que la forma en que lo hacía antes; de igual modo aprende a usar su habla interna y sus imágenes para regular una eficaz conducta de enfrentamiento.

3. Son cambiadas las estructuras cognitivas del cliente, los supuestos básicos implícitos y su habitual estilo de pensar.

Para ello, la terapia puede verse como progresando a través de tres fases que en la práctica pueden solaparse o no:

1. Fase de autoobservación, en la que el cliente se convierte en un observador de sus propias conductas. De esta manera llega a ser consciente de una serie de datos relevantes que antes le habían pasado desapercibidos (por ejemplo, relación entre pensamientos o imágenes y estados emocionales indeseables, o entre situaciones del entorno y respuestas emocionales, etc.). También se produce un efecto que él llama de traslación que consiste en un trasvase del léxico del terapeuta (constructos teoréticos, estilos de atribución, etc.), al modo de interpretar su mundo y su experiencia por el propio cliente. Esto a su vez trae de la mano dos consecuencias terapéuticamente importantes: ofrece al cliente una interpretación de sus problemas probablemente más benigna que la dada inicialmente por el sujeto, y en segundo lugar, permite darle una forma al problema que se pres- 
ta a una solución. Esto último abre expectativas positivas para el cliente, lo cual constituye un ingrediente de capital importancia para todo proceso terapéutico (Frank, 1974; Seligman, 1975).

2. En esta segunda fase, se trata de desarrollar pensamientos y conductas incompatibles con las manifestaciones del problema. Debido a que el cambio no suele producirse de un modo súbito, sino que se da a través de un proceso en el que se ven entremezclados pensamientos y conductas adaptativas con otras de signo contrario, es preciso continuar con la reconceptualización de los problemas del cliente, asegurándose de que posee los requisitos conductuales necesarios para enfrentarse con sus problemas, que aprende a controlar sus pensamientos $y$ sus conductas durante sus actividades diarias y que gradualmente aumenta la consistencia de estas nuevas habilidades. Debido a que el cambio cognitivo y el conductual se muestra interactivo, deben utilizarse estrategias combinadas para acelerar el cambio. Si la modificación de la conducta es la forma más eficaz para cambiar las cogniciones (Mahoney, 1979; Bandura, 1977 b), y de otro lado Bandura (1977 b) ha sugerido que el sentido de la autoeficacia requiere no sólo la confianza en que uno pueda producir la conducta requerida, sino también una creencia en que se conseguirán los resultados deseados, el diseño del terapeuta debería incluir el que las nuevas conductas se realizaran: $a$ ) «in vivo»; $b$ ) donde exista una elevada probabilidad de que la conducta evoque la respuesta deseada; c) en condiciones que lleven al cliente a atribuir su éxito a su propia capacidad, más que a las circunstancias externas (Bandura, 1977 b).

Pero para que el sujeto ponga en marcha sus habilidades de enfrentamiento debe aprender de manera consciente a reconocer las señales que evocan respuestas desadaptativas, iniciando su entrenamiento con las de baja intensidad, a fin de poner en marcha sus mecanismos de autocontrol, hasta que este tipo de respuestas incompatibles se hayan automa- tizado y devengan en sobreaprendidas. Meichenbaum intenta presentar aquí la otra cara de la moneda, el que un cambio cognitivo puede dar lugar también a cambios conductuales.

3. En esta tercera fase, se trata de consolidar los cambios, de promover la generalización y de crear una base para mantenerlos.

Se parte del supuesto de que la forma en que un cliente interpreta el cambio que se da en él, influirá en el grado de su generalización y de su mantenimiento. Para ello es necesario que el cliente reconozca que una transformación importante se ha llevado a efecto, y que ha sido debida a un cambio en él mismo más que a circunstancias externas. El cambio debe darse no sólo en su relación con el terapeuta, sino más esencialmente en su vida diaria. Para favorecer la conciencia del cambio es necesario mantener un registro objetivo de las conductas. Para aumentar la atribución del cambio a sí mismo es importante conceptualizar desde un principio la terapia como un proceso educacional, de entrenamiento en habilidades. Por otro lado, si el sujeto es capaz de alcanzar una comprensión clara a la hora de explicar cómo ha conseguido un cambio positivo, tenderá en un futuro a generalizar la estrategia utilizada y a mantenerla. También es preciso enfatizar que la reaparición de los problemas es posible $y$ debe verse como normal. Que si surgen recaídas el cliente debe interpretarlas como una señal para enfrentarse, y no como un fallo. Puede ayudarnos hacer que los clientes anticipen las recaídas y la forma con la que se enfrentarán a las conductas problema (ver Marlatt y Gordon, en prensa).

En definitiva, se trata de una teoría «evidencial» del cambio, en la que el terapeuta ayuda al cliente a generar, recoger y reconstruir los datos. Sus ingredientes básicos pueden encontrarse en las teorías del autocontrol, en los procedimientos de las terapias cognitivas y en la tecnología conductual. 


\section{VI.3. Procedimientos y epistemología}

Vamos a referirnos ahora a la cuestión capital de distinguir entre procedimientos para provocar el cambio y las distintas tazones que se alegan para explicarlo. Atendiendo a las variables preferidas por los distintos procedimientos de intervención, y salvando las limitaciones propias de todo intento de clasificarlas, estas orientaciones podrían agruparse en cuatro tipos:

1. La de aquellos que dan prioridad al manejo de las variables contextuales, suponiendo que sin alterar el programa de contingencias no existe cambio, y considerando que emociones $y$ cogniciones serán modificadas del mismo modo. Skinner sería un representante típico.

2. Aquellos otros que inciden preferentemente sobre las emociones y secundariamente sobre conductas motores y cogniciones. Estaría representado por Wolpe, Eysenck y otros miembros de la corriente neoconductista mediacional E-R.

3. Un tercer grupo que acentúa más directamente sus intervenciones sobre las cogniciones como foco principal para promover el cambio. «Las emociones, en su mayor parte, son una forma de pensamiento ilógico...», decía Ellis (Ellis, 1961, p. 29).

4. Por último, quedarían aquellos que podríamos denominar «interaccionistas», y que de modo explícito utilizan en sus diseños más de un sistema de variables de la triada clásica (Lang, 1968). Bandura, Beck y Meichenbaum podrían ser algunos de sus representantes.

Si esto puede establecerse desde el punto de vista de los procedimientos de intervención, el núcleo de los procesos de cambio se sitúa de un modo muy distinto según los autores. En la epistemología del cambio, debemos agrupar a Ellis, Bandura, Beck y Meichenbaum por considerar que no hay cambio sin que se dé cierta reordenación cognitiva, al menos para generar un cambio duradero y generalizado. En Ellis se supone pre- ciso un cambio en el conjunto de creencias irracionales del sujeto; en Bandura es preciso modificar los niveles de autoeficacia; en Beck se requiere un cambio en el estilo de pensamiento del individuo; y en Meichenbaum parece apuntarse la necesidad de una remodelación de la estructura cognitiva y las metacogniciones. $\mathrm{Y}$ éstos son los objetivos que parecen señalarse en el proceso terapéutico, si bien para ello podemos valernos de procedimientos cognitivos -la «nueva terapia verbal», como ha indicado Ledwidge $(1978,1979)-$, y/o conductuales, en proporciones variables según el problema y los autores. La distinción establecida por Bandura (1977 b) entre procedimientos y procesos de cambio parece estar en la base de estos objetivos y sirve de justificación (ver Meichenbaum y Cameron, 1980).

Para Skinner, el problema epistemologico está claro, el medio controla la conducta, aun cuando podríamos señalar que la interacción de los tres sistemas de variables podría ser aceptado por este autor, al menos en el sentido de que son formas de conducta y están sometidas a las mismas leyes (Skinner, 1953). De todos modos, las fuentes del cambio son manifiestas en Skinner, y recientemente se ha reafirmado en ellas (Skinner, 1977). Las razones que limitan la metodología de investigación skinneriana y su propia filosofía de la conducta le hacen dar un peso especial a las variables del entorno, de manera que las variables mentales carecen de fuerza para explicar el cambio de conducta. Esto, a su vez, no equivale a negar el papel que puede y debe jugar una psicología centrada en el estudio de los procesos mentales, la cual puede conseguir un status por derecho propio aunque circunscrita, a juicio de Skinner, a un recinto epifenoménico.

Wolpe, por otro lado, asegura que la terapia de conducta siempre fue cognitiva, que las tres modalidades conductuales - cognitiva, motora y autonómica- se dan en la mayoría de las conductas humanas, que lo que hay que entender es que los tres tipos de fenómenos 
son simplemente funciones del sistema nervioso, y que a la vez son formas de conducta sometidas a las mismas leyes (Wolpe, 1978). Wolpe representa la postura «fisiologizada» del conductismo skinneriano y de las teorías del condicio namiento aplicadas a humanos. Su epistemología del cambio se podría centrar fundamentalmente en una interacción entre variables fisiológicas y medio.

De todo esto podríamos concluir que han sido los procedimientos de intervención, que en cada orientación se consideraban más fiables para promover el cambio, los que en ocasiones han hecho creer que se hablaba de epistemología. En realidad la interacción es la postura epistemológica más extendida, si bien la disposición de «herramientas» terapéuticas eficaces ba orientado la intervención en una u otra dirección según su «fabricante».

A nuestro juicio, la CBM se mueve en un campo esencialmente empírico y pragmático, los problemas epistemológicos son hasta cierto punto secundarios y «serán las técnicas establecidas empíricamente y fundadas teóricamente las que serán aceptadas por el campo. [...] la pureza de su herencia filosófica podrá ser interesante pero no de importancia esencial» (Mahoney y Kazdin, 1979, página 1046). La necesidad o no de la modificación de conducta cognitiva es el tema de un debate epistemológico reciente en el que no podemos entrar más por falta de espacio (ver Wolpe, 1976, 1978; Dedwidge, 1978, 1979; Mahoney, 1979; Eysenck, 1979; Greenspoon y Lamal, 1978; Locke, 1979; Mahoney y Kazdin, 1979; Meichenbaum, 1979; Observer, 1978; Wilson, 1978; Skinner, 1977; Meichenbaum y Cameron, 1980).

Nosotros sometemos la interpretación de este problema a las propias leyes de interacción que conocemos. Es decir, la epistemología del cambio y los instrumentos utilizados para favorecerlo van indisolublemente unidos. Si la selección e interpretación de los datos de la experiencia están íntimamente ligadas a nues- tros presupuestos epistemológicos, no es posible hablar de procedimientos de intervención sin referencia a una epistemología del cambio. Podremos darle más o menos relevancia a este aspecto de la cuestión, pero en todo caso habremos de apechugar con las consecuencias, de todo orden, que de esta postura fundamental se deriven. En este sentido, estamos cerca de Skinner al considerar el pensamiento como una forma de conducta pero quizás las características específicas de este campo requieran una reelaboración que aún no se ha acometido adecuadamente. Una concepción operante mediacional es el objetivo de nuestras reflexiones actuales, y aun a costa de incurrir inicialmente en verbalizaciones vacías de contenido operacional, creemos que el proyecto merece la pena.

\section{VI.4. Discusión y resultados en la CBM}

En 1977 Bandura indicó que los métodos de tratamiento basados conductualmente eran significativamente más efectivos en producir cambios sobre medidas objetivas y subjetivas múltiples de las funciones psicológicas que aquellos otros métodos que descansan sobre procedimientos verbales, imaginarios o vicarios (Bandura, 1977 b). Es decir, que de manera general, los tratamientos basados en la ejecución eran superiores a técnicas imaginarias tales como la desensibilización sistemática, el flooding simbólico y el modelado encubierto. ¿Qué pasa al comparar las técnicas verbales con las que usan de modo especial las imágenes? Di Loreto, en 1971, en un trabajo bien diseñado, encontró que la desensibilización sistemática era más efectiva que la RET para clientes con ansiedad interpersonal. En cambio la RET aumentó la autoestima personal en las interacciones. El coping parece ser un factor crítico en la eficacia de las terapias. Pero de nuevo el coping participante, como es el caso del modelado de ejecución, es superior al coping imaginario, como pueda ser el modelado encubierto. Así lo han demos- 
trado Thase y Moss en 1976 en conducta fóbica. En un trabajo reciente de Emmelkamp (Emmelkamp et al., 1980), sobre el tratamiento de la conducta obsesivo-compulsiva, el entrenamiento en autoinstrucción no mejoró en nada la eficacia del método de exposición. En otro trabajo del mismo autor de 1978, la exposición prolongada «in vivo» fue muy superior a la técnica de reestructuración cognitiva directa en un grupo de agorafóbicos, produciendo a su vez una reestructuración más rápida y eficaz (ver también Ellis, 1979). Parece, por tanto, que en el tratamiento de las conductas con base en la ansiedad interpersonal, de las fóbicas y de las obsesivo-compulsivas, la exposición es un ingrediente aconsejable. Pero, ¿qué pasa en una conducta como la depresiva en donde las distorsiones cognitivas parecen ser más claras y extensas?

Taylor y Marshall (1977) encontraron que la CBM (basada en Beck, 1967, $1976,1979)$ era superior a procedimientos exclusivamente conductuales (basados en Lewinsohn, 1979), y a otros estrictamente cognitivos, en sujetos depresivos voluntarios. Sus resultados coinciden con los encontrados por Shaw (1977). Fuchs y Rehm (1977) encontraron igualmente que la combinación de técnicas conductuales y cognitivas (basadas en el modelo de autocontrol de Rehm, 1977), daban mejores resultados que otras técnicas de control no específicas y que los sujetos de la lista de espera. Rehm, Fuchs, Roth, Kornblith y Roman (1975) comprobaron que el mismo método era superior al ofrecido a un grupo con entrenamiento en habilidades sociales. En definitiva, hay evidencia de la eficacia de los procedimientos de la CBM en pacientes depresivos externos no bipolares (Hollon y Beck, 1979).

Pero la eficacia de los procedimientos cognitivo-conductuales también se va extendiendo a las poblaciones clínicas. Marlatt y Gordon (en prensa) lo han presentado en bebedores, Turk, Meichenbaum y Genest (1980) en el dolor transitorio o crónico, Linehan (1979) en problemas de asertividad, Goldfried (1977, 1979), Heppner (1978) y Lange y Jakubowski (1976) en la ansiedad, Kendall y Finch (1979) en impulsividad y Rook y Hammen (1977) en disfunciones sexuales. La revisión general de Hollon y Kendall (1979) hace un pormenorizado examen de estos extremos.

Volviendo al campo de la depresión, los resultados más espectaculares se dieron al comprobar la superioridad de la aproximación CBM sobre la farmacoterapia en poblaciones con depresión grave (Rush, Beck, Kovacs y Hollon, 1977). En este caso, la diferencia más notable se estableció en el porcentaje de recaídas, ya que los procedimientos de Beck «incluyen experiencias de aprendizaje altamente específicas, que proveen al pacientc de estrategias para combatir los factores psicológicos que le predisponen a la depresión» (Rush, Beck, Kovacs y Hollon, 1977, p. 35).

En resumen, los procedimientos de intervención de la CBM parecen ofrecer un campo prometedor. Nuestra experiencia personal en el uso de estos procedimientos también se inclina a su favor. Pero quedan muchas cuestiones prácticas y teóricas por resolver. ¿Cuáles son los factores determinantes de la generalización y el mantenimiento del cambio? ¿Qué factores inciden, y cómo podemos alterarlos, en el procesamiento inadecuado de la información?, ¿cómo deben secuenciarse las distintas técnicas de intervención en cada caso?, ¿son factores aislados, o una combinación de ellos los que determinan el cambio?, ¿'es siempre preciso un cambio de conducta manifiesta para conseguir un cambio terapéutico?, ¿qué papel juega la intervención verbal, fuera de promover a la acción o a la exposición, en el cambio terapéutico?, ¿cómo se pasa del aprendizaje voluntario al sobreaprendizaje o conducta inconsciente?, si la intervención directa sobre la conducta manifiesta es el mejor modo de producir cambios cognitivos, ¿en qué casos, cuándo, cómo y por qué hemos de intervenir con técnicas cognitivas?, etc., etc. 
A pesar de los muchos problemas aún pendientes, la CBM ha logrado en la última década una notable aproximación integradora al llegar a establecer procedimientos de intervención eficaces en varias áreas de aplicación. También han surgido teorías de requerimiento (Bandura, 1977 b; Meichenbaum, 1977), con lo que se ha enriquecido considerablemente una síntesis teorética con sólida base ex- perimental. Si bien estas investigaciones se han centrado especialmente en las condiciones del cambio, el trabajo clínico y experimental futuro apunta hacia un análisis más extenso y profundo acerca del mantenimiento del cambio y su generalización, así como a la construcción y valoración experimental de instrumentos de evaluación conductual-cognitivos.

\section{Resumen}

En esta revisión, que alcanza hasta finales del 80 , se efectúa un repaso de la literatura más relevante en el campo de la CBM. Tras un análisis de los problemas generales de la corriente conductista que han facilitado su aparición así como de otras influencias específicas y de su conexión con diversos sistemas de terapia, se pasa a una breve exposición de los principales procedimientos de intervención terapéutica. Las teorías de «requerimiento» del cambio y el estudio de su epistemologia apuntan a un núcleo «interaccionista» en la mayoría de los procedimientos. La necesidad de una concepción operante mediacional en humanos y la discusión de los resultados en los procedimientos de la CBM cierran el estudio.

\section{Summary}

In this review which reaches the end of 1980 a survey of the most relevant published works on the field of the $\mathrm{CMB}$ has been made. After an analysis of the general problems of the behaviorist corrent which have favorised the apparition of the $C M B$, besides other more specific influences and of its relationships with several systems of therapy is made a brief explanation of the most important procedures of therapeutic intervention. The theories of "requirement» of change and the study of its epysthemology are pointing towards an «interactionist» nucleus in the main part of the procedures. The need of an operative mediational conception on human beings and the discussion of the results on the CMB procedures close this study.

\section{Resumé}

Dans cet etude que arrive jusqu'an la fin du 1980, on réalise une revisión a la literature plus relevé du champ de la CBM. Aprés une analyse des problemes generaux du mouvêment behaviorisme qui ont falicitè l'aparition de la CBM, ainsi que des autres influences plus specifiques et de sa liaison avec divers systemes de therapie, on pase a une bref description des principales procédès de intervention therapeutique. Les teories de «requisition» du changement et l'etude de sa epistemologie signalent sur une noyeau *interaccioniste" dans la plus part des procédès. Avec le besoin d'une conception operante mediationel dans les humanies et la discussion des resultats des procédès de la CBM on finalise l'etude. 


\section{Referencias}

ADLER, A.: Understanding Human Nature, Nueva York, Greenberg, 1927. (Hay traducción castellana: Conocimiento del hombre, Madrid, Espasa-Calpe, 1962, 1." ed. en 1947.)

Allport, G.: Becoming, New Haven, Yale University Press, 1955.

Bandura, A.: «Psychotherapy as a learning process", Psychological Bulletin, 5 (2), 1961.

Bandura, A.: Principles of behavior modification, Nueva York, Holt, Rinehart and Winston, 1969.

Bandura, A. (Ed.): Psychological modeling: Conflicting theories, Chicago, Aldine-Atherton, 1971.

Bandura, A.: «Behavior theory and models of man», American Psychologist, 29, 859-869, 1974.

Bandura, A.: Social Learning theory, Englewood Cliffs, Nueva York, Prentice-Hall, 1977 a.

BANDURA, A.: «Self-efficacy: toward a unifying theory of behavior change», Psychological Review, 89, 191-215, 1977 b.

BANDURA, A.: «Reflections on self-efficacy», Advances on Bebavior Researcb and therapy, 1, 237-269, 1978.

BandurA, A.: "The self and mechanisms of agency», en J. Suls (Ed.): Social psychological perspectives on the self, Hillsdale, N. J., Erlbaum, 1980 (en prensa).

BaYes, R.: ¿Chomsky o Skinner? La génesis del lenguaje, Barcelona, Fontanella, 1977.

BECz, A. T.: «Thinking and depression: I. Idiosyncratic content and cognitive distorsions», Archives of General Psychiatry, 9, 324333, 1963.

BECK, A. T.: Depression: clinical, experimental and tbeoretical aspects, Nueva York, Harper and Row, 1967. (Vuelto a publicar como: Depression, causes and treatment, Philadelphia, University of Pennsylvania Press, 1970.)

BECK, A. T.: Cognitive therapy and emotiond disorders, Nueva York, International Universities Press, 1976.

Beck, A. T. y Mahoneт, M.: «Schools of throught?», American Psychologist, 34, 93-98, 1979.

Becr, A. T.; Rush, J.; SHAw, E., y Emerx, G.: Cognitive therapy of depression, Nueva York, Guilford Press, 1980.

BEM, D.: «Self-perception: An alternative interpretation of cognitive dissonance phenomena», Psychological Review, 74, 183-200, 1967.

Breger, G. L. y Mc Gaugh, J.: "Critique and reformulation of "learning theory": Approaches to psychotherapy and neurosis», Psychological Bulletin, 63, 338-358, 1965.

BREWER, W.: "There is no convincing evidence for operant or classical conditioning in adults humans", en W. WeImer y D. PALermo (Eds.): Cognition and the symbolic processes, Hillsdale, N. J., Erlbraum Associates, 1974.

Cautela, J. R.: «Covert conditioning», en A. Jacobs y L. B. Sachs (Eds.): The psychology of private events: perspectives on covert response systems, Nueva Jersey, Academic Press, 1971.

CoNe, E.: The practice of autosuggestion, Nueva York, Doubleday, 1922.

CHomsxy, N.: «A review of verbal behavior in B. F. Skinner», Language, 35, 26-58, 1959.

Dr Loreto, A.: Comparative psychotberapy, Nueva York, Aldine-Atherton, 1971.

Dollard, J. y Mrller, N. E.: Personality and psychotherapy, Nueva York, MoGraw-Hill, 1950. (Hay traducción castellana: Personalidad y psicoterapia, Bilbao, Desclee de Brouwer, 1977.)

DuBors, P.: The psychic treatment of nervous disorders, Nueva York, Funk and Wagnalls, 1909. (Primera edición en 1907.)

DuLANY, D. E.: «Awareness, rules and propositional control: a confrontation with S-R behavior theorym, en T. R. Dixon y D. L. HorTon (Eds.): Verbal behavior and general theory, Englewood Cliffs, Nueva York, Prentice Hall, 1968.

D'ZuRILla, T. J. y GoldFrIed, M. R.: «Problem solving and behavior modification», Journal of Abnormal Psycbology, 78, 107-126, 1971.

Ellis, A.: «A note the treatment of agovaphobics with cognitive modification versus prolonged exposure in vivo», Bebavior Research and Therapy, 17, 162-164, 1979.

ELLIS, A.: Reason and emotion in psychotherapy, Nueva York, Stuart, 1962. (Hay traducción castellana: Razón y emoción en psicoterapia, Bilbao, Desclee de Broưwer, 1980.)

Ellis, A. y Grieger, R.: Handbook of rational-emotive therapy, Nueva York, Springer Publishing Co., 1977.

Eulis, A. y HarPer, R. A.: A guide to rational living. Nueva Jersey, Prentice Hall, 1961. (Hay traducción castellana: Psicoterapia racional emotiva, México, Herrero Hnos. Sucs., S. A., 1962.)

Emmelkamp, P. M.; Kuipers, A. C., g EgGeraAT, J. B.: \&Cognitive modification versus prolonged exposure "in vivo": a comparison with agoraphobics as subjets", Bebavior Researcb and Therapy, 16, 33-41, 1978.

Emmelikamp, P. M.; Helm, M.; Zanten, B. L., y Plochc, I.: «Treatment of obsesive-compulsive patients: the contribution of self-instructional training to the effectiveness of exposures, Behavior Researcb and Tberapy, 18, 61-66, 1980. 


\section{Estudios}

Eysenck, H. J.: Behavior therapy and the neurosis, Oxford, Pergamon Press, 1960.

Eysenck, H. J.: Experiments in bebavior therapy, Oxford, Pergamon Press, 1964. (Hay traducción castellana: Experimentos en terapia de la conducta, 3 vol., Madrid, Ed. Fundamentos, 1979.)

EySENCK, H. J.: «Behavior therapy and the philosophers», Behavior Research and Therapy, 17, $511.514,1979$.

Foreyt, J. P. y Rathjen, D. P. (Eds.): Cognitive behavior therapy: research and application, Nueva York, Plenum Press, 1978.

FRANCE, J.: Persuasion and bealing: a comparative study of psychotherapy, Baltimor, John Hopkins Press, 1961 (revisado en 1974).

Fuchs, C. Z. y Regn, L. P.: «A self-control behavior therapy program for depression», Journd of Consulting and Clinical Psycbology, 45, 206-215, 1977.

GoLDFRIED, N. R.: «Systematic desensitization as training in self-control», Journal of Consulting and Clinical Psychology, 37, 228-234, 1971.

GoldFried, M. R.; Decenteceo, E. T., ₹ WeInberg, L.: «Systematic rational reestructuring as self-control technique», Bebavior Therapy, 5, 247-254, 1974.

GOLDFRIED, M. R.: «The use of relaxation and cognitive relabeling as coping skills», en R. STUART (Ed.): Bebavioral Self-management, Nueva York, Brunner/Mazel, 1977.

GolDFRIED, M. R.: "Anxiety reduction through cognitive-behavioral intervention», en P. KeNDALI. y S. Hollon (Eds.): Cognitive-bebavioral interventions: theory, researcb and procedures, Nueva York, Academic Press, 1979.

Greenspoon, J. y Lamal, P.: «Cognitive behavior modification. Who needs it?», The Psychological Record, 28, 343-357, 1978.

HEPPNER, P.: «A review of problem-solving literature and its relationship to the counseling process», Journal of Counseling Psychology, 25, 366-375, 1978.

Hollon, S. D. y Becr, A. T.: «Cognitive therapy of depression», en P. Kendall y S. Hollon (Eds.): Cognitive-behavioral interventions: theory, researcb and procedures, Nueva York, Academic Press, 1979.

Homme, L. E.: «Perspectives in psychology: XXIV. Control of coverants, the operants of the mind», The Psychological Record, 15, 501-511, 1965.

Horton, D. L. y Turnage, T. W.: Human learning, Englewood Cliffs, N. J., Prentice Hall, 1976.

JANET, P.: The major symptoms of hysteria, Londres, McMillan, 1907.

Jennings, L.; Crosland, R.; Loveless, S.; Murray, J., y George, S.: «Cognitive control of extintion of classically conditioned pupillary response», The Psychological Record, 28, 193$205,1978$.

JoHnson, W.: People in guandaries, Nueva York, Harper, 1946.

KANFER, F. H.: «Self-regulation: Research issues and speculations», en C. NeURINGER y J. L. MiCHAEL (Eds.): Bebavior Modification in Clinical Psychology, Nueva York, Appleton-CenturyCrofts, 1970 (original de 1967).

Karnes, M.; TESEA, J., y Hodgins, A.: «The effects of four programs of classroom intervention on the intellectual and language development of 4-years old disadvantaged children», American Journal of Ortbopsycbiatry, 40, 58-76, 1970.

KAzDIN, A. E.: «Covert modeling and the reduction of avoidance behavior», Journal of Abnormal Psycbology, 81, 87-95; 1973.

KAzDIN, A. E.: «Effects of covert modeling and modeling reinforcement of assertive behavior», Journal of Abnormal Psychology, 83, 240-252, 1974.

KeLLY, G.: The psycbology of personal constructs, Nueva York, Norton, 1955.

KenDALL, P. y FINCA, A.: «Developing non-impulsive behavior in children: cognitive-behavior estrategies for self-controlm, en P. KEndall y S. Hollon (Eds.): Cognitive-Behavior interventions: theory, research and procedures, Nueva York, Academic Press, 1979.

Kendall, P. y Hollon, S. (Eds.): Cognitive-bebavioral interventions: Tbeory research and procedures, Nueva York, Academic Press, 1979.

Kock, S.: «Psychology and emerging conceptions of knowledge as unitary», en T. W. WANN: Bebaviorism and phenomenology, Chicago, Chicago University Press, 1964.

KorzYBSKr, A.: Science and sanity, Lancaster, Pa., Lancaster Press, 1933. (Edición en rústica: San Francisco Institute for General Semantics, 1973.)

KuHN, T. S.: The structure of scientific revolutions, University of Chicago Press, 1962. (Hay traducción castellana: La estructura de las revoluciones científicas, México, Fondo de Cultura Económica, 1975 [primera edición, 1971].)

LANG, P. J.: «Fear reduction and fear behavior: problems in treating a construct», en I. $\mathbf{M}$. SCHLIEN (Ed.): Research in Psychotherapy, vol. III, Washington, D.C.A.P.A., 1968.

LANGE, A. y JAKUBOWSK, P.: Responsible assertive bebavior: cognitive bebavioral procedures for trainess, Champaing, Illinois, Research Press, 1976.

Lazarus, R.: Psycbological stress and tbe coping process, Nueva York, Mc Graw-Hill, 1966. 
LEDWIDGE, B.: "Cognitive-behavior modification: a step in the wrong direction?", Phychological Bulletin, 85, 353-375, 1978.

LEDWIDGE, B.: «Cognitive-behavior modification or new ways to change minds: Reply to Mahoney and Kazdin», Psychological Bulletin, 85, 1050-1053, 1979.

LEWINSOHN, P. M. y ATwood, G. E.: «Depression: A clinical-research approach», Psychotherapy: Theory, Research and Practice, 6, 166-171, 1969.

LIEBERT, R. M. y MORRIS, L. W.: «Cognitive and emotional components of tests anxiety: A distinction and some initial data», Psychological Reports, 20, 975-978, 1967.

LINEHAN, M. M.: «Structured cognitive-behavioral treatment of assertion problems», en P. C. KENDALl y S. V. Hollon (Eds.): Cognitive-Bebavioral interventions: Theory, research and procedures, Nueva York, Academic Press, 1979.

LOCKE, E.: «Behavior modification is not cognitive and other myths: reply to Ledwidge», Cognitive Tberapy and Research, 3, 141-146, 1979.

Low, A.: Mental bealth through will training, Boston, Christopher Publishing, 1950.

LuRIA, A.: The role of speed in the regulation of normal and abnormal behaviors, Nueva York, Liveright, 1961.

LURIA, A.: "Speech and formation of mental processes», en M. Cole y I. MALTzMAN (Eds.): $A$ handbook of contemporary soviet psychology, Nueva York, Basic Books, 1969.

McCorquodale, K.: «On Chomsky's review of Skinner's verbal behavior», Journal of the Experimental Analysis of Bebavior, 13, 83-99, 1970.

Mahoney, M. J.: Cognition and Behavior Modification, Cambridge, Bellinger, 1974.

Mahoney, M. J.: «Personal science: A cognitive learning therapy», en A. Ellis y R. Grieger (Eds.): Handbook of rational psychotberapy, Nueva York, Springer, 1977.

Manoney, M. J.: «Psychotherapy and the structure of personal revolutions», en M. MaronEy (Ed.): Cognition and clinical science, Nueva York, Plenum Press, 1979.

MaHONEY, M. J. y ARKNoFf, D.: «Cognitive and self-control therapies», en S. Garfield y A. BERGIN (Eds.): Handbook of psychotberapy and bebavior cbange, Nueva York, Wiley, 1978.

MaHoner, M. J. y Kazdin, A.: «Cognitive behavior modification: misconceptions and premature evaluation", Psychological Bulletin, 86, 10441049, 1979.

Maxtzman, I.: «Theoretical conceptions on semantic conditioning and generalization», en T. R. DIxON y D. L. HoRTon (Eds.): Verbal bebavior and general bebavior theory, Englewood Cliffs, Nueva York, Prentice Hall, 1968.

Maltzman, I.: «Orienting in classical conditioning and generalization of the galvanic skin response towards: an overview», Journal of Experimental Psycbology: General, 106, 111-119, 1977.

MarlatT, A. y GoRdon, J.: «Determinants of relapse: Implications for the maintenance of behavior change», en Davison (Ed.): Behavioral Medicine: Changing bealt lifestyles, Nueva York, Brunner/Mazel, en prensa.

MARLETT, N. J. y WATSON, D.: «Test anxiety and inmediate or delayed feedback in a test-like avoidance task», Journal of Personality and Social Psycbology, 8, 200-203, 1968.

MeICHENBauM, D.: «Cognitive factors in behavior modification: Modifying what clients say to themselves», en C. M. Franks y G. T. WILson (Eds.): Annual Review of Behavior Therapy Theory and Practice, vol. I, Nueva York, Brunner/Mazel, 1973.

Meichenbaum, D.: Cognitive bebavior modification, Morristown, Nueva York, General Learning Press, 1974.

Meichendaum, D.: «Toward a cognitive theory of self-control», en G. SchWartz \& D. SAPIRo (Eds.): Consciousness and self regulation, vol. I, Nueva York, Plenum Press, 1976.

MeICHENBaus, D.: Cognitive Behavior modification: An integrative approacb, Nueva York, Plenum Press, 1977.

Meichenbaum, D.: «Cognitive Behavior Modification: The need for a faire assessment», Cognitive Therapy and Research, 3, 127-130, 1979.

MEICHENBAUM, D. y ButLER, L.: "Toward a conceptual model for the treatment of test anxiety: Implications for research and treatment», en I. SARASON (Ed.): Test Anxiety: Theory, Researcb and Applications, Nueva Jersey, Lawrence Erlbaum, 1980.

Meichenbaum, D. y Cameron, R.: Stress inoculation: $A$ skills training approach to anxiety management, Unpublished manuscript, University of Waterloo, 1973.

Meichenbaum, D. y Cameron, R.: «Cognitive behavior modification», en C. Franks y T. WILson (Eds.): Handbook of Behavior Tberapy, Nueva York, Guilford Press, 1980.

Miller, G. A.; Galanter, E. H., y PrIbram, K. H.: Plans and the structure of bebavior, Nueva York, Holt, Rinehart and Winston, 1960.

MILLER, N. E.: The influence of past experience upon the transfer of subsequent training. Unpublished Doctoral dissertation, Yale University, 1935.

MuRRAY, E. J. y JACoBson, L. I.: «Cognition and learning in traditional and behavioral therapy», 


\section{Estudios}

en S. Garfield y A. Bergin (Eds.): Handbook of Psycbotherapy and bebavior change, Nueva York, Wiley, 1978.

NeIsser, U.: Cognitive Psychology, Nueva York, Meredith Publ. Co., 1967. (Hay traducción castellana: Psicología cognitiva, México, Trillas, 1976.)

Nottermann, J. M.; Schoenfeld, W N., y Bersh, P. J.: «A comparison of three extinction procedures following heart rate conditioning», Journal of Abnormal and Social Psychology, 47, 674-677, 1952.

ObServer, T. H.: «The recycling of cognition in psychology», Psycbological Record, 28, 157$160,1978$.

PAStore, N.: «The role of arbitrariness in the frustration-aggression hypothesis», Journal of Abnormal and Social Psycbology, 47, 728-731, 1952

Paulov, I. P.: Selected Works, Moscú, Foreing Languages Publishing House, 1955.

Peterfreund, E. y SchWartz, J. T.: Information, systems and psychoanalysis, Nueva York, International Universities, 1971.

Phillips, E.: Psychotherapy: A modern theory and practice, Nueva York, Prentice Hall, 1957.

Platonov, K. I.: The word as a physiological and tberapeutic factor, Moscú, Foreign Languages Publishing House, 1959.

Price, D. J. S.: Little science, big science, Nueva York, Columbia University Press, 1963. (Hay traducción castellana: Hacia una ciencia de la ciencia, Barcelona, Ariel, 1973.

Rachman, S.: «Introduction to behavior therapy», Behavior Researcb and Therapy, 1, 3-15, 1963.

RACHMAN, S. y EySENCx, H. J.: «Raplay to a "critique and reformulation" of behavior therapy», Psychological Bulletin, 65, 165-169, 1966.

Raimy, V.: Misunderstanding of the self, San Francisco, Jossey-Bass, 1975.

RAZRAN, G.: «A cuantitative study of meaning by conditioned salivary technique (semantic conditioning)», Science, 90, 89-91, 1939.

Razran, G.: «The observable unconscious and the inferable conscious in current soviet psychophysiology», Psychological Review, 68, 81-147, 1961.

RAzRAN, G.: aRussian physiologists' psychology and Ámerican experimental psychology», Psycbological Bulletin, 63, 42-64, 1965.

RrHM, L. P.: «A self-control model of depression», Behavior Tberapy, 8, 787-804, 1977.

Rehm, L. P.; Fuchs, C.; Roth, D.; Kornblith, S., y Roman, J.: Self-control and social skills training in the modification of depression, Unpublished manuscript, University of Pittsburg, 1975.

Richelie, M.: «Analyse formele et analyse fonctionelle du comportement verbal», Bulletin de Psychologie, 304, xxvi, 5-9 1972-73.

Roox, K. y Hammen, C.: «A cognitive perspective on the experience of sexual arousal», Journal of Social Issues, 33, 7-29, 1977.

RoTTER, J. B.: Social learning and clinical psychology, Englewood Cliffs, Nueva York, Prentice Hall, 1954.

Rush, A. J.; Becr, A. T.; Kovacs, M., y Hollon, S.: «Comparative efficacy of cognitive therapy and pharmacotherapy in the treatment of depressed outpatients», Cognitive Therapy and Research, 1, 17.37, 1977.

Seligman, M. P.: Helplessness, San Francisco, Freeman, 1975.

ShafFer, L. F.: «The problem of psychotherapy», American Psycbologist, 2, 459-467, 1947.

SuAw, B. F.: «Comparison of cognitive therapy and behavior therapy in the treatment of depres sion», Journal of Consulting and Clinical Psycbology, 45, 543-551, 1977.

ShuRE, M. y Sprvack, G.: Problem solving techniques in cbilrearing, San Francisco, JosseyBass, 1978.

SKINNER, B. F.: Science and Human Bebavior, Nueva York, McMillan, 1953. (Hay traducción castellana: Ciencia y conducta bumana, Barcelona, Fontanella, 1970.)

SkINNER, B. F.: Verbal Behavior, Nueva York, Appleton-Century-Croffts, 1957.

SKINNER, B. F.: «Behaviorism at fifty», Science, 140, 951-958, 1963.

SxINNER, B. F.: «Why I am not a cognitive psychologist», Behaviorism, 5, 1-10, 1977.

SNYGGS, D. y ComBS, A.: Individual Bebavior, Nueva York, Harper, 1949.

SPIELBERGER, C. D. y $\mathrm{DE}$ NIKE, L. D.: «Descriptive behaviorism versus cognitive theory in verbal operant conditioning», Psychological Review, 73, 306-326, 1966.

Sprvacr, G.; Platt, J. J., y ShuRE, M. D: The problem-solving approach to adjustment, San Francisco, Jossey-Bass, 1976.

Sprvacr, G. I Sture, M. D.: Social adjustment of young cbildren: $A$ cognitive approach to solving realife problems, San Francisco, Jossey-Bass, 1974.

Stauts, A W.: Learning, language and cognition, Nueva York, Holt, Rinehart and Winston, 1968.

StaAts, A. W.: «Social behaviorism, human motivation, and the conditioning therapies», en B. MAHFR (Ed.): Progress in experimental personality research, Nueva York, Academic Press, 1970. 
StaAts, A. W.: Social behaviorism, The Dorsey Press, 1975. (Hay traducción castellana: Conductismo Social, México, El Manual Moderno, 1979.)

SuIN, R. M. y RuchardSon, F.: «Anxiety management training: A nonspecific behavior therapy program for anxiety control", Bebavior Therapy, 2, 498-510, 1971.

Sullivan, H. S.: Conceptions of modern psychiatry, Washington, William Alanson, White Foundation, 1947.

TAYLOR, F. G. y Marshall, W. L.: «Experimental analysis of cognitive-behavioral therapy for depression», Cognitive Therapy -and Researcb, 1, 59-72, 1977.

Thase, M. E. у Moss, M. K.: «The relative efficacy of covert modeling procedures and guided participant modeling on the reduction of avoidance behavior», Journal of Bebavior Therapy and Experimental Psychiatry, 7, 7-12, 1976.

Tolman, E. C.: Purposive bebavior in animals and men, Nueva York, Appleton-Century-Croffs, 1932.

TURx, D. C.: Cognitive control of pain: A skills-training approacb, Unpublished Master's Thesis, University of Waterloo, 1975.

TuRk, D.; MeIchensaum, D. y Genest, M.: Cognitive-bebavioral treatment of pain, Nueva York, Guilford Press, 1980.

Ullman, L. P.: "On cognitions and behavior therapy», Bebavior Therapy, 1, 201-204, 1970.

VeLTEN, E.: \&A laboratory task for induction on mood states», Bebavior Research and Therapy, 6, 473-482, 1968 .

VyGors xY, L. S.: Thought and the language, Cambridge, Mass., MIT Press, 1962. (Hay traducción castellana: Pensamiento y Lenguaje, Buenos Aires, Ed. La Pléyade, 1977.) (Edición rusa original de 1934.)

WIEST, W. M.: \&Some recent criticism of behaviorism and the learning theory», Psychological Bulletin, 67, núm. 7, 1967.

WILIINS, W.: «Desensitization. Social and cognitive factors underlying the effectiveness of Wolpe's procedure», Psycbological Bulletin, 76, 311-317, 1971.

WILsoN, G. T.: «Cognitive behavior therapy: paradigm shift or passing phase?», en J. P. FoREYT y D. P. RATHJEN (Eds.): Cognitive bebavior therapy: Researcb and application, Nueva York, Plenum Press, 1978.

Wolpe, J.: Psychotberapy by reciprocal inbibition, Palo Alto, Cal., Stanford University Press, 1958.

Wolpg, J.: «Behavior therapy and its malcontents. II. Multimodal eclecticism, cognitive exclusivism and "exposure" empiricism», Journal of Bebavior Therapy and Experimental Psycbiotry, 7, 109-116, 1976.

WoLPE, J.: «Cognition and causation in human behavior and its therapy», American Psychologist, $33,437-446,1978$. 